\title{
GEOGRAFIAS DE EXÍLIO: MARIO BENEDETTI, UM INTELECTUAL LATINO-AMERICANO
}

Miriam Lidia Volpe*

RESUMO:

\begin{abstract}
Examina-se o perfil de Mario Benedetti - escritor uruguaio de relevante produção - para uma reflexão sobre o papel do intelectual latino-americano e seu lugar de enunciação. Adotando a perspectiva do ensaio biográfico, matizada pelo suporte teórico e pela crítica textual, considerou-se sua trajetória a partir dos conceitos de exílio, insílio e desexilio.
\end{abstract}

PALAVRAS-CHAVE: intelectual latino-americano, lugar de enunciação, identidade nacional, exílio.

Mario Benedetti (1920 - ) é um marco na literatura do Uruguai e da América Latina, um escritor de obra extensa e multifacetada que inclui, em 50 anos de produção, romances, contos, poesias, ensaios, crônicas, crítica literária, teatro e jornalismo. Cerca de sessenta títulos que ultrapassaram trezentas edições (e um milhão e meio de exemplares), obras traduzidas em mais de vinte línguas, várias adaptações delas para a televisão e para o cinema, além de seus poemas terem sido musicados por "cantautores" internacionais (Alfaro, 1986; Bebberfal1, 1974; Paoletti, 1996; Paredes, 1975, entre outros).

A vigência da obra de Benedetti não se baseia só no reconhecimento popular evidente de suas obras, mas também através de sua preocupação com o rigor no fazer literário que teve um respaldo acadêmico internacional. Podem ser destacadas, dentre as manifestações mais recentes, o título de Doutor Honoris Causa da Universidade de Milão, assim como o da Universidade de Alicante em 1998, e, em 1999, o XIII Prêmio

* Doutora em Letras: Estudos Literários (Área de concentração: Literatura Comparada), 2002. 


\section{EMTESE}

Belo Horizonte, v. 7, p. I-I I0, dez. 2003

Rainha Sofia de Poesia Ibero-Americana na Espanha, conferido pela Universidade de Salamanca, além do Prêmio ao Labor Intelectual outorgado pelo Ministério de Educação e Cultura do Uruguai, e o título de Professor Emérito da Universidad de la República. 0 escritor figurou, também, recentemente, junto com Ernesto Cardenal e Mario Vargas Llosa, como candidato ao XIII Prêmio Internacional Menéndez Pelayo, de Madri, e recentemente ganhou o prêmio Planeta, em Buenos Aires (Alemany et alii, 1998; Anthropos, 1992).

No Brasil, foram publicadas inicialmente traduções de alguns de seus poemas, no volume Antologia Poética (1989) e de dois romances, A trégua (1989) e Quem de nós (1992). Em 1997, uma de suas primeiras narrativas, Gracias por el fuego, escrita em 1965 e já traduzida para vinte línguas, foi lançada aqui, ao mesmo tempo em que aparecia, em Buenos Aires, um de seus mais recentes trabalhos, Andamios. Logo depois, em 1998, publicou-se A borra do café. Como foi apontado em entrevista ao escritor para o Jornal do Brasil, Gracias por el fuego, apesar de ter sido escrito na década de 60, encontra hoje, no Brasil, uma recepção interessante, na medida em que seu texto denuncia o conformismo e o quietismo amparados no mito democrático e neoliberal, fazendo uma crônica da impotência coletiva e refletindo sobre a crise moral de uma geração que esta submersa na corrupção e a violência.

Benedetti revela-se, a meu ver, como um autor com quem ainda se pode dialogar, principalmente no que se refere à possibilidade de revisão teórica de sua obra, que representaria uma importante contribuição para as discussões que tomam lugar no cenário crítico e literário brasileiro. Dada a relevância deste escritor uruguaio na literatura continental, considera-se sua inscrição na tradição dos intelectuais, escritores e críticos latino-americanos que, empenhados em quebrar a hegemonia e re-localizar a escritura buscaram - e buscam ainda - negociar espaços de enunciação (Canclini, 1990; Candido, 1972; Piglia, 1991; Santiago, 1978; Schwartz, 1992; Trigo, 1990). Ou seja, que buscam propor uma auto-interpretação de sua história, arte e cultura, sem se considerar obrigados a aceitar o diagnóstico, não raras vezes, onipotente, que, sobre tais aspectos, elabora o mundo desenvolvido, mesmo que este seja expresso através de altos expoentes de sua intelligentsia. Benedetti reconhece, nos ensaios dos brasileiros A. Candido e S. Santiago, do colombiano J. Mejía Duque, do peruano A. Cornejo-Polar, do cubano Fernández Retamar, do chileno 
N. Osorio, do argentino G. Canclini, publicados nos últimos anos, o esforço para propor uma dimensão e um ponto de vista latino-americanos, tanto na crítica literária como na história das idéias, sem por isso desconsiderar o aporte da Europa e dos Estados Unidos, com o qual considera que podem concordar, ou discordar, de igual para igual (Benedetti, 1995a e 1996a).

Estudar e refletir sobre Benedetti no Brasil implica trazer ao leitor brasileiro o perfil desse escritor latino-americano através de uma biografia intelectual crítica valendo-se de fragmentos significativos de sua vida, ou "biografemas" (Barthes, 1971), aos que se entretecem reflexões teóricas, principalmente no que concerne aos termos chave implícitos neste trabalho: o exílio, o intelectual latinoamericano e a nação, o lugar de sua enunciação. Implica, também, dar a conhecer, através de algumas de suas obras, a expressão de suas idéias não só no campo teórico, em seus ensaios críticos, mas também na arte poética de sua ficção. Portanto, os fragmentos biográficos e as reflexões teóricas são ilustrados pela análise literária de obras consideradas representativas dentro dos contextos apresentados.

A escolha do termo "geografias" define o percurso da pesquisa. Ao refletir sobre situações de exílio, e suas variantes - o insílio e o desexílio sugere-se uma ênfase na dimensão espacial, no sentido de estar, atravessar, sair, voltar a lugares, cidades, países, fronteiras, pontes, assim como também, de forma metafórica, de atitudes, estados de espírito, visões de mundo, ideologias. No entanto, é incluída, também, uma dimensão temporal, numa proposta de articulação dos tempos de vida de Mario Benedetti com os tempos da cultura em que sua trajetória se inscreve, dado que o escritor se autoproclama tradutor e testemunha desses tempos (Lago, 1996). Dessa forma, e por seu intermédio, ficariam divulgadas, também, partes da história e da cultura uruguaias.

Os conceitos tanto de "exílio", como de "intelectual", e até de "latinoamericano", são problemáticos e têm sido amplamente discutidos por diferentes ramos da academia através dos tempos. Faz-se necessário, portanto, fazer um recorte na abordagem dos mesmos.

Quanto ao exílio - situação tão antiga quanto a narrativa da expulsão de Adão e Eva do Paraíso - e suas conseqüências já foram estudados e cantados por mestres de todas as épocas. Portanto, parece relevante estudar alguns aspectos em 


\section{EMTESE}

Belo Horizonte, v. 7, p. I-I I0, dez. 2003

particular que foram detectados na obra ensaística e ficcional de Benedetti e discutidas por vários estudos críticos internacionais (Giabbai, 1992; Zeitz, 1986).

Em primeiro lugar, o exílio em seu sentido formal e legal, como fenômeno massivo inédito na América Latina, provocado pelas ditaduras do século passado e seus efeitos não só sobre os indivíduos, mas sobre as identidades nacionais e a cultura, e sofrido por inúmeros intelectuais, entre os quais, o próprio Benedetti, exilado na Argentina, no Peru, em Cuba e na Espanha (Benedetti, 1986a; Bevan, 1990; Rama, 1998; Robinson, 1994; Rutheford, 1990).

Em segundo lugar, os aspectos positivos, até não intencionais, do exîlio, que aparecem na obra do escritor uruguaio: não só o que há de compaixão e caridade, correndo paralela à crueldade do homem para com seus semelhantes ao proscrevê-los (Tabori, 1972), como também a hospitalidade com que alguns países recebem os exilados e as contribuições que estes últimos podem oferecer à vida intelectual e literária de suas novas pátrias (Benedetti, 1986b e 1988).

Além da acepção de exílio como afastamento territorial do lugar ao qual se pertence - o destierro, (deslocamento que traz consigo a idéia de perda, de desenraizamento) - parece relevante deslocar o marco histórico e coletivo do mesmo e considerar - além do componente de mudança geográfica, considerado como secundário (Ilie, 1980) - o seu aspecto de estrutura interna, condição mental, estado de ânimo, atitude. Tal atitude teria sido detectada pelo autor uruguaio, em determinado momento do Uruguai em crise, no cidadão montevideano, com quem ele se preocupa e a quem transforma em personagem de sua ficção (Benedetti, 1984 e 1988b). Isso porque, mesmo dentro de seu próprio país, esse cidadão parece viver alienado da realidade, numa espécie de exílio interior. Uma alienação, no sentido filosófico e humanístico, como o exílio do exercício responsável do poder do homem: o exílio da livre e responsável aegis dos poderes de iniciativa, para tentar reverter a situação (Benedetti, 1960).

Raramente, nos estudos sobre o exílio, se tem falado do vazio deixado pelo êxodo, nem de suas repercussões sobre as pessoas que ficam (Ilie, 1980). Nesse sentido, aparece, na obra de Benedetti, um exílio residencial, ou insílio, sofrido pelos cidadãos que foram forçados pelas ditaduras a adotar uma atitude passiva e uma 
semi-impotência que os destitui de sua autonomia moral e de sua iniciativa psicológica e também pelos que foram encarcerados e destituídos de todos os seus direitos (Benedetti, 1993).

Dado que o exílio, como conceito e como experiência, pode ser considerado bilateral se percebido em sua inter-relação com o não-exílio, implícito na nostalgia do que foi perdido, ou deixado para trás, e no desejo da volta, destaca-se o termo cunhado pelo escritor - desexilio - que aparece discutido em sua ficção (Benedetti, 1996) e em seus ensaios (Benedetti, 1986a). Mas as dificuldades do retorno ao país que os exilados mantinham em seus sonhos e utopias sempre foram muitas (Sosnowski, 1987). Para Benedetti, a Espanha passou a ser um lugar privilegiado, lar adotivo que, na impossibilidade de ter o Uruguai imaginado utopicamente, constitui-se como um espaço de onde o autor mira, de fora, extramuros, sua terra. Dividido entre 0 Uruguai e a Espanha, o escritor recorre ao termo contranostalgia para definir sua nova concepção de pátria. Após ter perseguido tantos sonhos em suas tantas viagens por tantas geografias, ele sente que se converteu em um verdadeiro entroncamento de culturas. Junto a uma concreta esperança de regresso, junto à sensação inequívoca de que a saudade torna-se, para ele, numa nova noção de pátria, é possível vislumbrar que esse lugar estaria ocupado pela contranostalgia do que se tem no exterior e vai ser deixado: a curiosa nostalgia do exílio em plena pátria (Benedetti, 1995b). Em conseqüência, Benedetti transforma-se em um "ser entre duas águas" e decide adotar uma situação fronteiriça, de semidesexílio, ao compartir sua vida entre Montevidéu e a Madri que significa muito para ele.

Para o intelectual uruguaio, parece haver uma única maneira de viver sua identidade: como estrangeiro, como estrangeiro em casa, ou como em casa de estrangeiros, pois a "estrangeiridade" se transformou na única casa possível. Uma casa que parece ser aquela predestinada para o criador, pois o exílio não faz mais do que acrescentar mais uma dimensão, ou um avatar, ao que já seria seu estado natural e exclusivo. A condição fundamental da literatura, a condição autêntica de qualquer escritor seria uma forma de exílio, de ruptura, de autoproscrição. Enquanto a crisálida da criação se libera dentro do artista, ele já estaria no limiar do exílio. 0 exílio estaria dentro dele antes de 1 he ser imposto e passaria a revelar-se logo que começa sua migração e se estende sua busca. 


\section{EMTESE}

Belo Horizonte, v. 7, p. I-I I0, dez. 2003

Quanto ao difícil e escorregadio termo "intelectual", seu campo semântico tem sido, e ainda é, objeto de constantes definições (e talvez isso aconteça, como parece ser costume nos processos de significação, uma luta pelo poder). Resulta difícil, portanto, falar do problema sem recorrer a generalizações simplificadoras. Reduzem-se, assim, estas considerações, à figura do intelectual latino-americano, como homem de letras, com o poder de produzir e transmitir idéias e visões de mundo, através do poder ideológico da palavra e da imagem e que, portanto, pode ter influência, como homem público com um papel específico na sociedade.

A proposta que destaca o lugar das letras na conquista do continente parece estender-se até os nossos dias (Rama, 1985; Mignolo, 1995). Na América Latina da descolonização, o papel e a atividade do intelectual existiram bem antes que a palavra fosse usada para nomeá-10. Nos cenáculos, nas revistas literárias, as polêmicas e suas obras foram definindo essa categoria, embora os participantes não cogitassem utilizar esse rótulo para si mesmos (Marques, s/d ; Achugar, 1998).

Existe, na América, uma tradicional ligação do intelectual com a política e uma ativa participação sua na formação das nações, que coincidiu com a origem dos estados e a formação das identidades culturais, tal como aparece marcada na maioria dos estudos referentes ao próprio conceito de nação (Anderson, 1991; Bhabha, 1990; Hobsbawm, 1991; Renan, 1882; Yurkievich, 1986). As relações entre a política e a cultura têm alimentado controvérsias internacionais infindáveis (Barros Lemes, 1988; Bobbio, 1992; Said, 1994). As posições extremas seriam a que considera que o intelectual engajado politicamente trairia sua condição de sacerdote guardião da cultura (Benda, 1980) e a que afirma que se ele se recusa ao compromisso torna-se estéril, professoral, isolado em uma torre de marfim (Gramsci, 1979). As posições intermédias propõem que 0 intelectual defenda uma sociedade mais justa através de valores de força moral sem afiliações políticas e até desligado da problemática das nacionalidades (Said, 1994).

Mario Benedetti considera-se simplesmente um homem comum, talvez melhor treinado para o raciocínio e a fantasia, mas alguém acossado pelos mesmos, ou similares, dilemas, escrúpulos, ansiedades que o resto de seus próximos. A diferença mais visivel, segundo o autor, reside em que as disjuntivas do intelectual, como as do político, tomam estado público e afrontam o vespeiro da controvérsia, enquanto 
que as do cidadão comum se refugiam na assepsia do privado (Benedetti, 1995). Nesse sentido, o escritor uruguaio se incorpora a todo um arquipélago de poetas latinoamericanos (Parra, Gelman, Cardenal, Sabines, 0. Paz, J. Cabral de Melo Neto, Lhin, Cisneros) que adotam o estilo coloquial (Alemany, 1997; Benedetti, 1981; Retamar, 1975; Mansour, 1979) em busca de uma comunicação e uma cumplicidade com seu leitor. Levar as problemáticas cotidianas de seu próximo para a poesia, implicaria, também, em seu engajamento para com a realidade latino-americana com a intenção de transformála em uma sociedade mais justa e menos dependente.

Houve um momento em que os intelectuais europeus - antes, durante e depois das terriveis experiências do nazismo e do fascismo - estiveram imersos em seu contexto social e político, de Antonio Machado a Thomas Mann, de Jean Paul Sartre a Peter Weiss, de Césare Pavese a Rafael Alberti - nem todos militaram nas mesmas trincheiras, mas nenhum deles deixou de se pronunciar, de se comprometer, de se solidarizar. Hoje, no entanto, o compromisso passou a ser mal visto. Para Benedetti, o intelectual latino-americano, dentro ou fora de seu lugar de origem, permanece imerso na problemática de sua nação e do continente e, ao escutar seus clamores, não se pode negar ao engajamento e fechar os olhos ao que acontece ao seu redor.

Neste novo milênio, junto com o fim da História, dos grandes relatos, das economias nacionais, das fronteiras científicas, em sua condição de homem público, que acarreta pressões sobre o comportamento, o intelectual tende a afastarse da vida pública para evitar correr o risco de ser chamado de utópico. 0 escritor uruguaio, no entanto, que se propôs a contribuir na luta por uma sociedade mais justa e manteve sempre uma coerência ética dentro de seu projeto estético, assume a utopia como postura vital e se expõe ao defendê-la: "Para mim, a utopia continua sendo o motor que move o homem. A humanidade avançou sempre graças à utopia, que nasce como uma ponte de uma realidade injusta para outra mais justa. Nesses tempos de decaimento da solidariedade e da promoção da conquista individual, continuo acreditando nas conquistas espirituais e na justiça" (Benedetti, apud Anthropos, 1992).

Mario Benedetti, escritor comprometido, é, sobretudo, comprometedor, produtor de uma mensagem que envolve e provoca o leitor para levá-10 a desenvolver uma sensibilidade, uma consciência e uma ousadia suficientes que the permitam 


\section{EM TESE}

Belo Horizonte, v. 7, p. I-I I0, dez. 2003

responder a cada conjuntura inesperada da vida com uma atitude mais lúcida e mais consciente da sua atuação em prol de uma sociedade mais justa. Afinal, é no exercício da leitura, ato de solidão compartilhada, que o leitor atravessa a ponte e se comunica com o escritor, com seus pares e também, essencialmente, consigo mesmo.

ABSTRACT :

The role and locus of enunciation of the Latin American intellectual is examined through a discussion of Mario Benedetti, a Uruguaian writer whose literary career is approached through the concepts of exile, insile and desexilio in a critical biographical essay that intertwines theoretical considerations and the textual analysis of some of his works.

KEY WORDS: Latin American intellectual, locus of enunciation, exile, national identities. 
REFERÊNCIAS BIBLIOGRÁFICAS

ALEMANY BAY, Carmen; MATAIX, Remedios; ROVIRA, José Carlos (Ed.). Mario Benedetti: Inventario cómplice. Alicante: Universidad, 1998.

ALEMANY BAY, Carmen. Poética coloquial hispanoamericana. Alicante: UA, 1997.

ALFARO, Hugo: Mario Benedetti: detrás de un vidrio claro. Montevidéu: Trilce, 1986.

ACHUGAR, Hugo (Comp.). La fundación por la palabra. Montevidéu: FHCE/Universidad de la República, 1998.

ACHUGAR, Hugo; CAETANO, Gerardo (Comp.). Mundo, región, aldea: identidades politicas culturales e integración regional. Montevidéu: Trilce, 1995.

ANDERSON, Benedict. Imagined Communities. Londres: Verso, 1991.

BARTHES, Roland. Sade, Fourier, Loyola. Lisboa: Edições $70,1971$.

BARROS-LEMES, Alvaro. Intelectuales y política: polémicas y posiciones, años 60 y 70. Montevidéu: Monte Sexto, 1988.

BEBBERFALL, Freda. Thematic continuity and changing emphasis in the work of Mario Benedetti.1974. Tese (Doutorado)-University of Wisconsin, Madison.

BENDA, Julien. The treason of the intellectuals. Trad. Richard Aldington. Londres: Norton, 1980.

BENEDETTI, Mario. El país de la cola de paja. Montevidéu: Asir, 1960.

BENEDETTI, Mario. Literatura uruguaya, siglo XX. Montevidéu: Alfa, 1963.

BENEDETTI, Mario. Los poetas comunicantes. México: Marcha Ed., 1981.

Benedetti, Mario. Poemas de la oficina. Madri: Visor, 1984 .

BENEDETTI, Mario. El desexilio y otras conjeturas. Bs. Aires: Nueva Imagen, 1986a.

BenedetTI, Mario. Primavera con una esquina rota. Bs. Aires: Nueva Imagen, 1986b.

BENEDETTI, Mario. El escritor latinoamericano y la revolución posible. Bs. Aires: Nueva Imagen, 1987.

BENEDETti, Mario. Montevideanos. Montevidéu: Arca, 1988a.

Benedetti, Mario. Geografías. Montevidéu: Arca, 1988b.

BenedetTI, Mario. Perplejidades de fin de siglo. Montevidéu: Cal y Canto, 1993.

BENEDETTI, Mario. El ejercicio del criterio. Bs. Aires: Seix Barral, 1995a.

Benedetti, Mario. La borra del café. Montevidéu: Cal y Canto, 1995b.

BENEDETTI, Mario. Cultura entre dos fuegos. Montevidéu: Univ. de la República, 1996a.

BENEDETTI, Mario. El olvido está lleno de memoria. Montevidéu: Cal y Canto, 1996b. 


\section{EM TESE}

Belo Horizonte, v. 7, p. I-I I 0, dez. 2003

Benedetti, Mario. Andamios. Bs. Aires: Seix Barral, 1996C.

BHABHA, Homi (Ed.). Nation and narration. Londres: Routledge, 1990.

BEVAN, David. Literature and exile. Amsterdam: Rodopi, 1990 .

BOBВI0, Norberto. Os intelectuais e o poder: dúvidas e opções dos homens de cultura na sociedade contemporânea. Trad. Marco Aurélio Nogueira. São Paulo: USP, 1992.

CAMPA, Román de 1a. Latinoamérica y sus nuevos cartógrafos. Revista Iberoamericana, Stanford, p. 697718, jul.-dez. 1996.

CANDID0, Antonio. Literatura e subdesenvolvimento. In: FERNÁNDEZ MORENO, César (Org.). América Latina em sua literatura. São Paulo: Perspectiva, 1972. p. 343-362.

GIABBAI, Gloria da Cunha. El exilio, realidad y ficción. Montevidéu: Arca, 1992.

FERNANDEZ RETAMAR, Roberto. Para una teoría de la poesía hispanoamericana y otras aproximaciones. Havana: Casa de las Américas, 1975.

GARCIA CANCLINI, Nestor. Culturas híbridas: estrategias para entrar y salir de la modernidad. México: Grijalbo, 1990 .

GRAMSCI, Antonio. Os intelectuais e a organização da cultura. Trad. Carlos N. Coutinho. Rio de Janeiro: Civilização Brasileira, 1979.

HISTORIA del Uruguay. (Vários autores) Montevidéu: Colección Banda Oriental. 1990-96.

HOBSBAWM, Eric. Nation and nationalism since 1780. Cambridge: University of Cambridge Press, 1990.

ILIE, Paul. Literature and inner exile. Londres: John Hopkins University Press, 1980.

LAGO, Sylvia. Mario Benedetti: cincuenta años de creación. Montevidéu: Universidad de la República, 1996.

MANSOUR, Mónica. Tuya, mía, de otros: la poesía coloquial de Mario Benedetti. México: UNAM, 1979.

MARQUES, Reinaldo. Arcádias, utopias, secularização, dissidência. Pré-publicação para o "Projeto História Comparada das Formações Culturais na Literatura LatinoAmericana", Toronto, Canadá. (manuscrito)

MATHIEU, Corina. Los cuentos de Mario Benedetti. Nova Iorque: Peter Lang, 1983.

MIGNOLO, Walter. Decires fuera de lugar: sujetos dicentes, roles sociales y formas de inscripción. Revista de Crítica Literaria Latinoamericana. Lima/Berkeley, n. 41, p. 9-31, 1995.

NOGUEROL, Francisca (Ed.). Los espejos las sombras. Salamanca: Ediciones de la Universidad, 1999.

PAOLETTI, Mario. El Aguafiestas. Benedetti: la biografía. Madri: Alfaguara, 1996.

PAREDES, Luis. Evolución ideológica de Mario Benedetti a través de su obra literaria. 1974. Tese (Doutorado) California University, Irvine. 
PIGLIA, Ricardo. Memoria y tradición. In: CONGRESSO ABRALIC, 2, 1991, Belo Horizonte. Anais... Belo Horizonte: UFMG, 1991. p. 60-66.

RAMA, Ángel. A cidade letrada. Trad. Emir Sader. São Paulo: Brasiliense, 1985.

RAMA, Ángel. La riesgosa navegación del escritor exiliado. Montevidéu: Arca, 1998.

RENAN, Ernest. Qu'est-ce qu'une nation? Paris: CalmannLevy, 1882.

RICO, Alvaro (Comp.). Uruguay cuentas pendientes: dictaduras, memorias y desmemorias. Montevidéu: Trilce, 1995.

ROBINSON, Marc (Ed.). Altogether elsewhere: writers on exile. Londres: Faber \& Faber, 1994.

RoCCA, Pablo (Comp.). Mario Benedetti: 45 años de ensayos críticos. Montevidéu: Cal y Canto, 1993.

RUTHEFORD, Jonathan. Identity, community, culture, difference. Londres: Lawrence \& Wishart, 1990.

SAID, Edward W. Representations of the intellectual. The 1993 Reith Lectures. Londres: Vintage, 1994.

SANTIAGO, Silviano. Vale quanto pesa. Rio de Janeiro: Paz e Terra, 1982.

SANTIAGO, Silviano. Uma literatura nos trópicos. São Paulo: Perspectiva, 1978.

SARL0, Beatriz. Una modernidad periférica: Buenos Aires 1920 y 1985. Bs. Aires: Nueva Visión, 1988.

SCHWARZ, Roberto. Ao vencedor as batatas. 4. ed. São Paulo: Duas Cidades, 1992.

SOSNOWSKI, S. (0rg.). Represión, exilio y democracia: la cultura uruguaya. Montevidéu: Banda Oriental, 1987.

SOUZA, Eneida M. de. Sujeito e identidade cultural. Revista Brasileira de Literatura Comparada, Niterói, n. 1, p. 34-40, 1991.

TABORI, Pau1. Anatomy of exile. Londres: Harrarp, 1972.

TRIGO, Abril. Caudillo, estado, nación: literatura, historia e ideología en Uruguay. Gaithesburg: Hispamérica, 1990.

YURKIEVICH, Saúl (Org.). Identidad cultural de Iberoamérica en su literatura. Madri: Alhambra, 1986.

ZEITZ, Eileen M. La crítica, el exilio y más allá en las novelas de Mario Benedetti. Montevidéu: Amesur, 1986. 